\title{
BMJ
}

\section{Group therapy for adolescents with repeated self harm: randomised controlled trial with economic evaluation}

\author{
J M Green, professor of child psychiatry , ${ }^{1,6}$ A J Wood, consultant adolescent psychiatrist, ${ }^{2}$ M J Kerfoot, \\ honorary professor of mental health studies, ${ }^{1} \mathrm{G}$ Trainor, nurse consultant, ${ }^{3} \mathrm{C}$ Roberts, reader in biostatistics, ${ }^{1} \mathrm{~J}$ \\ Rothwell, research associate, ${ }^{1}$ A Woodham, research assistant, ${ }^{1} \mathrm{E}$ Ayodeji, lecturer in child and adolescent \\ mental health, ${ }^{4}$ B Barrett, lecturer in health economics, ${ }^{5}$ S Byford, reader in health economics, ${ }^{5}$ R Harrington, \\ professor of child psychiatry (deceased) ${ }^{1}$
}

${ }^{1}$ Psychiatry Research Group University of Manchester Manchester M13 9PL, UK

${ }^{2}$ Tier 4 Child and Adolescent Mental Health Services, Young People's Centre, Chester, UK

${ }^{3}$ Greater Manchester West Mental Health NHS Foundation Trust,

Manchester

${ }^{4}$ School of Nursing and Midwifery, University of Salford, Salford

${ }^{5}$ Centre for the Economics of Mental Health Institute of

Psychiatry, King's College London, London, UK

${ }^{6}$ Manchester Biomedical Research Centre and Academic Health Sciences Centre, Manchester

Correspondence to:Jonathan Green jonathan.green@manchester.ac.uk

Cite this as: BMJ 2011;342:d682 doi:10.1136/bmi.d682

\section{ABSTRACT}

Objective To examine the effectiveness and costeffectiveness of group therapy for self harm in young people.

Design Two arm, single (assessor) blinded parallel randomised allocation trial of a group therapy intervention in addition to routine care, compared with routine care alone. Randomisation was by minimisation controlling for baseline frequency of self harm, presence of conduct disorder, depressive disorder, and severity of psychosocial stress.

Participants Adolescents aged 12-17 years with at least two past episodes of self harm within the previous 12 months. Exclusion criteria were: not speaking English, low weight anorexia nervosa, acute psychosis, substantial learning difficulties (defined by need for specialist school), current containment in secure care. Setting Eight child and adolescent mental health services in the northwest UK.

Interventions Manual based developmental group therapy programme specifically designed for adolescents who harm themselves, with an acute phase over six weekly sessions followed by a booster phase of weekly groups as long as needed. Details of routine care were gathered from participating centres.

Main outcome measures Primary outcome was frequency of subsequent repeated episodes of self harm. Secondary outcomes were severity of subsequent self harm, mood disorder, suicidal ideation, and global functioning. Total costs of health, social care, education, and criminal justice sector services, plus family related costs and productivity losses, were recorded.

Results 183 adolescents were allocated to each arm (total $n=366)$. Loss to follow-up was low ( $4 \% \%)$. On all outcomes the trial cohort as a whole showed significant improvement from baseline to follow-up. On the primary outcome of frequency of self harm, proportional odds ratio of group therapy versus routine care adjusting for relevant baseline variables was 0.99 ( $95 \%$ confidence interval 0.68 to $1.44, \mathrm{P}=0.95)$ at 6 months and $0.88(0.59$ to $1.33, P=0.52$ ) at 1 year. For severity of subsequent self harm the equivalent odds ratios were 0.81 (0.54 to1.20,
$\mathrm{P}=0.29)$ at 6 months and 0.94 (0.63 to $1.40, \mathrm{P}=0.75)$ at 1 year. Total 1 year costs were higher in the group therapy arm ( $£ 21781)$ than for routine care ( $£ 15372$ ) but the difference was not significant $(95 \% \mathrm{Cl}-1416$ to 10782 , $\mathrm{P}=0.132$ ).

Conclusions The addition of this targeted group therapy programme did not improve self harm outcomes for adolescents who repeatedly self harmed, nor was there evidence of cost effectiveness. The outcomes to end point for the cohort as a whole were better than current clinical expectations.

Trial registration ISRCTN 20496110

\section{INTRODUCTION}

Self harm in adolescents is a major public health problem in many countries. It is associated with recurrent psychosocial problems ${ }^{12}$ and poor long term outcome ${ }^{3}$ and it may mark an emerging personality disorder. ${ }^{4}$ Self harm tends to recur; the reported risk of repetition in adolescents ranges from 10\% within six months to $42 \%$ during a 21 -month follow-up, with a median recurrence of 5-15\% each year. ${ }^{5}$ The risk of suicide after self harm in adolescence is around 0.1$0.5 \%$ over 10 years ${ }^{26}$ with retrospective studies reporting a repetition rate of $36 \%$ over $10-12$ years $^{7}$ and lifetime mortality rates of $4-11 \% .^{89}$ Self harm shows comorbidity with axis I psychiatric disorders in $43 \%$ to $70 \%$ of cases, with evidence that the number of comorbid conditions is associated with increased risk of a serious suicide attempt. ${ }^{10}$ Around two thirds of children and adolescents presenting with self harm score positively for depressive disorders ${ }^{11-15}$; suicidal adolescents with chronic and recurrent affective illness are at increased risk of repetition. ${ }^{1116-18}$ The persistence of major depressive disorder predicts substantially increased risk of further self harm in young adulthood when other factors are controlled. ${ }^{19}$ The incidence of self harm is increasing in some areas of the UK. ${ }^{20}$

Self harming adolescents contribute substantially to the workload of health services, in terms of both emergency risk assessment and longer term management. A further substantial burden is placed on wider social 
care and education. At the time of a self harm event, the young person commonly presents to an accident and emergency department; current National Institute for Health and Clinical Excellence (NICE) guidance ${ }^{1}$ for England and Wales is for overnight medical hospital admission as a minimum response and more lengthy medical or psychiatric admission is often needed in situations of risk or more severe disorder. A followup study of young adults who had deliberately poisoned themselves as adolescents ${ }^{21}$ found that their lifetime service costs were significantly greater than those of matched controls. They used more service provided accommodation, special education, and hospital services, incurred greater criminal justice costs, and received more social security benefits.

Despite this large burden, very little is known about the cost-effectiveness of interventions. ${ }^{22}$ In one of the few studies to date, Byford and colleagues ${ }^{23}$ undertook a cost-effectiveness analysis of a home based social work intervention for children and adolescents who deliberately poisoned themselves. They found no significant differences between the two groups in terms of the main outcome measures or costs, although in a subgroup of children without major depression, suicidal ideation was significantly lower in the intervention group at follow-up with no significant differences in cost.

The design and delivery of effective treatments for this group are complex and have to accommodate considerable variations in presentation. ${ }^{1}$ A subgroup of patients needs emergency inpatient management; the majority require long term treatment approaches in the context of multi-agency partnerships. A Cochrane review of psychosocial and pharmacological treatments for self harm ${ }^{24}$ found continuing uncertainty about which forms of treatment are most effective and insufficient evidence against which to make firm recommendations. Across all age ranges, a promising additional benefit over standard care was found for problem solving therapy (summary odds ratio across five studies $0.70 ; 0.45$ to 1.11 ) and provision of an emergency contact card (summary odds ratio across two studies $0.45 ; 0.19$ to 1.07 ), but neither of these results reached statistical significance. The authors noted a number of key limitations across all studies reviewed. These included insufficient sample sizes, leading to possible type 2 errors in effectiveness estimates; lack of adequate description of the services used as comparison groups; and use of service data (usually further hospital attendance) rather than interview data to define the primary outcome of repetition, which could introduce biases in outcome estimates, owing to variation in service use and the possibility that the intervention itself could alter willingness to seek hospital help.

Hawton and colleagues ${ }^{24}$ noted that only two of the studies reviewed focused on adolescent self harm, despite the importance of the problem in this age group and the likelihood that the treatment needs of adolescents differ from those of adults. Trials of adolescent focused treatments are therefore of high priority to inform service provision. Harrington and colleagues ${ }^{15}$ tested a brief family intervention for adolescents (total $\mathrm{n}=149$ ) against standard aftercare and found no significant effect on repetition (odds ratio 1.02; 95\% CI 0.41 to $2.5 ; \mathrm{P}=0.97$ ). The same group then undertook a developmental group psychotherapy programme designed to focus on the multiple clinical problems typical in this population (depression, experience of abuse, behavioural disorder, substance misuse, poor self esteem and body image, and family conflict and disruption) and to combine effectively with other interventions (pharmacotherapy, individual and family therapies) using a group therapy format that was costeffective of clinician time. A pilot randomised trial of developmental group psychotherapy compared with routine care in 63 adolescents referred with repeated self harm to child and adolescent mental health services ${ }^{25}$ showed a significant relative reduction of repeated self harm over 29 weeks of follow-up (2/31 in developmental group psychotherapy versus $10 / 31$ in routine care; odds ratio $6.3 ; 95 \% \mathrm{CI} 1.4$ to 28.7$)$. The total number of self harm episodes per participant during follow-up was also lower for the treatment group (mean 0.6) than for the routine care group (mean 1.8), but this difference was not statistically significant. This trial was one of the few to have suggested effectiveness of an intervention in patients of any age. A replication in northern Australia, with remote supervision from the UK developing team $(\mathrm{n}=72)^{26}$ failed to show a treatment effect. This study, however, recruited from general referrals to child and adolescent mental health services where patients were identified to have self harming behaviour, rather than from specific self harm referrals, and it only recruited $57 \%$ of its target for analytical power.

The Assessment of Treatment In Suicidal Teenagers (ASSIST) trial reported here was intended as a definitive test of this group intervention using a large sample with a pragmatic design and including a detailed health economic evaluation. Our objective was to use a large parallel group randomised trial to compare the effectiveness and cost-effectiveness of developmental group psychotherapy plus routine care with that of routine care alone for adolescents presenting with repeated self harm in the previous year. We addressed some of the methodological weaknesses in previous studies identified by Hawton and colleagues ${ }^{24}$ by recruiting a large cohort size, making detailed description of routine treatment undertaken, and triangulating two independent interview based ascertainments of the primary outcome rather than using service data on hospital attendance.

\section{METHODS}

\section{Participants}

Participating centres were established child and adolescent mental health services teams in the northwest of England, who served substantial geographical areas and were experienced in the assessment and management of young people with self harm. They delivered 
the developmental group psychotherapy in partnership with the ASSIST research team.

Participants were adolescents aged between 12 years and 16 years 11 months who had presented with two or more episodes of self harm during the previous 12 months. In the context of this study "self harm" was deemed to include the non-accidental overdose of drugs or other toxic substances, or non-accidental self inflicted injuries such as scratching, cutting, burning, or strangulation. Exclusion criteria were non-English speakers, severe low weight anorexia nervosa, current psychotic illness, attendance at special learning disability school, current containment in secure care (young people in other forms of looked after care such as adoption, fostering, or non-secure residential units were, however, included).

\section{Interventions}

\section{Experimental treatment}

Developmental group psychotherapy was a manual based treatment specifically designed for self harming adolescents. ${ }^{25}$ The programme integrated techniques from a number of other therapies that have previously been applied to depressed or suicidal adolescents and their families, including cognitive behavioural therapy, dialectical behavioural therapy, and group psychotherapy. ${ }^{152728}$ Group goals were oriented around themes that previous research suggested were important in adolescents who harm themselves, such as poor peer relationships, bullying, and family problems. Adolescents learned strategies to deal with these difficulties using group based techniques such as role play. The groups had a rolling entry; young people started attending as soon as their initial assessment and randomisation were completed and attendance continued until the young person felt ready to leave. Therapists had a minimum of three years of relevant post-qualifying experience. They had initial training in fidelity to the model from AJW and GT (the original developers of the intervention), who also led subsequent regular supervision, comprising urgent telephone consultation during working hours and attendance at a monthly supervision group. In the base site, developmental group psychotherapy was provided by AJW and GT and included patients considered clinically challenging by other teams. All clinical groups were audiotaped or videotaped unless consent was withheld. Protocol adherence was measured at each centre from videotaped sessions (minimum four per site per year; total $n=32$ ) by experts independent of the therapy or training and blind to centre allocation. They used a modification for group work of a standard quality scale for cognitive behavioural therapy. ${ }^{29}$

\section{Routine care}

Local child and adolescent mental health services teams provided standard routine care according to their clinical judgment. By agreement, centres excluded any group intervention from routine care during the trial. Non-blinded research staff recorded the nature and intensity of the routine care delivered for each case during monthly telephone reviews with responsible clinicians. Local therapists delivering the group intervention were not involved with patients allocated to routine care except in emergencies. There was careful discussion with local teams regarding the avoidance of any contamination from the group treatment into routine care.

\section{Outcomes}

The primary outcome was the frequency of episodes of self harm over a defined period (12 months before baseline, 6 months before 6 month assessment, 6 months before end point). Research assessors, blind to treatment allocation, conducted a face to face interview with participants every three months from baseline, using a self harm interview schedule validated in previous studies. ${ }^{1215}$ Structured interviewing techniques were used to minimise recall bias towards more recent events and to get a profile of the pattern of self harm over the period. To further reduce recall and reporting biases, non-blinded research therapists independently conducted an additional monthly telephone interview with participant and family using the same schedule. These two assessments were conferenced with a senior supervisor, blinded to the case and the assessment point of the interview, and a consensus rating was made to act as the trial's primary outcome. The two assessments were also later analysed to look for systematic bias; none was found.

\section{Secondary outcomes}

Severity of self harm was evaluated blind from triangulated reports. It was defined as "mild" for superficial scratching or cutting only; "moderate" for an overdose or cutting that reached medical attention; and "severe" for harm resulting in substantial or life threatening physical sequelae, including extended hospital admission.

Mood disorder was assessed with the Mood and Feelings Questionnaire (MFQ) ${ }^{30}$, a 34 item self report questionnaire to measure depressive symptoms. The instrument was designed to assess the depressive symptom areas specified in the Diagnostic and Statistical Manual of Mental Disorders IV (DSM-IV) for major depressive disorder. A cut off of 28/29 discriminates between adolescents with major depression and those with sub-threshold depression or with no depressive disorder. ${ }^{31}$ The maximum score is 68 .

Suicidal ideation was measured with the Suicidal Ideation Questionnaire (SIQ). ${ }^{32}$ This self report questionnaire, consisting of 30 items rated $0-6$, captures the frequency of suicidal thoughts. A high score of 6 indicates numerous and regular suicidal thoughts; 0 indicates that no such thoughts have occurred. Scores greater than 40 indicate substantial suicidal ideation.

Global functioning was measured using the Health of the Nation Outcome Scales for Children and Adolescents (HoNOSCA), ${ }^{33}$ a semi-structured interview, which was completed by the blinded research assessor on the basis of accounts taken directly from the informant and parents or carers. It measures a broad range of outcomes on 13 subscales (including emotional 
symptoms, behavioural problems, substance abuse, school attendance problems, and peer relationships). Each subscale is interviewer rated on a five point scale (total score range 0 to 52 ). The higher the score, the greater the overall impairment in terms of mental health difficulties and social functioning. The instrument has been widely used in child and adolescent psychiatry services and is of known reliability and validity. It is sensitive to changes in mental state and psychosocial functioning over brief periods of time..$^{334}$

\section{Economic evaluation}

We undertook a cost-effectiveness analysis to answer the stated aims of the evaluation. A broad perspective was taken, including costs to health, social care, education, and criminal justice sectors. Costs of travel to intervention appointments and productivity losses to parents associated with their child's illness were reported separately in a sensitivity analysis to explore the economic impact on families. Data were collected at baseline and at six and 12 months' follow-up using the Child and Adolescent Service Use Schedule (CASUS) developed in previous Child and Adolescent Mental Health Services trials ${ }^{233536}$ and adapted to ensure all relevant services were included. At baseline, the schedule was used to obtain data for the previous six months. At six and 12 months' follow-up, it recorded data since the previous interview. Inpatient stays were known to be a key cost driver in child and adolescent mental health populations, ${ }^{37}$ so local National Health Service Trust hospital records were searched to ensure the accuracy of data about admission and length of stay. Attendance at intervention sessions was recorded by study therapists to ensure accuracy and the blindness of the researcher assessors.

All unit costs (in pounds sterling) were for the financial year 2005-6, the most recent financial year over which study data were collected. Discounting of costs and benefits was not necessary owing to the 12 -month timescale of the study. Intervention sessions were costed on the basis of the salary of the trial therapist plus overhead costs (administrative, managerial, and capital). Calculation of indirect therapist time, including preparation and supervision, was based on information provided by the trial therapists. Unit costs of all health, social care, education, and criminal justice sector services were taken from routine sources and were adjusted to reflect local costs wherever possible. ${ }^{38-48}$ Travel costs were self reported return fares or estimated motoring costs per hour. ${ }^{49}$ Productivity losses of the time parents took off work because of their child's illness were calculated using the human capital approach, which involves multiplying time off work by the individual's salary. ${ }^{50}$

\section{Sample size}

Our pilot study ${ }^{25}$ suggested that a $50 \%$ reduction in the frequency of self harm was possible as a result of the developmental group psychotherapy intervention. A separate survey of child psychiatrists in the UK North West National Health Service region estimated that a reduction of a third in frequency of self harm would be the minimum clinically important difference. Based on this more conservative 33\% target reduction in the numbers of self harm episodes between developmental group psychotherapy intervention and control, 312 cases (a 370 target allowing for $15 \%$ case attrition) were estimated to be necessary to achieve $80 \%$ power to detect this difference at the $5 \%$ level of significance with a Mann-Whitney (two sided) test for categorical data. This calculation was done with nQuery Advisor ${ }^{51}$ software with the frequency distribution derived from the pilot study. For the routine care group we used the frequency distribution of the routine care group of the pilot study and for the intervention group the frequency distributions of the routine care and developmental group psychotherapy intervention were weighted to give a rate ratio of $2 / 3$, which corresponds to a proportional odds ratio of approximately $50 \%$ for this distribution.

\section{Randomisation}

Randomisation was by remote telephone to the trial centre at Christie Hospital Manchester. Therapists completed an eligibility checklist, obtained written consent, and emailed the checklist to the randomisation centre. Allocation was by minimisation controlling for: high or low self harm (or $\geq 4$ episodes $<4$ episodes over the previous 12 months); presence of behavioural disorder (conduct disorder, oppositional defiant disorder, attention-deficit/hyperactivity disorder) or depressive disorder on standardised psychiatric interview (the schedule for affective disorders and schizophrenia for school aged children: present and lifetime version ${ }^{52}$ ); and presence or absence of high psychosocial risk (indexed from baseline interview by presence of social worker involvement, local authority accommodation, or chaotic lifestyle). Table 1 presents details. Variables included in the minimisation were chosen as likely to predict treatment response on the basis of previous published work.

\section{Allocation concealment}

The main outcomes were recorded by outcome assessors blinded to treatment allocation. Patients and parents were asked before the interview with the assessor not to reveal anything about treatment. The researcher never entered the building when treatments were being run. Assessor guesses of allocation following end point were no better than chance. All assessment interviews were audiotaped and a random sample rerated by an independent assessor blind to treatment allocation. It was not possible to blind clinicians in participating centres or the participants themselves to treatment allocation.

\section{Statistical methods}

All analyses were carried out using Stata Statistical Software Release $9 .^{53}$ Analysis of primary and secondary outcomes was by intention-to-treat subject to availability of data. An interim analysis with concealment of 
the allocation group suggested that the primary outcome measure (frequency of self harm) was very highly skewed. We therefore grouped the data for numbers of days with self harm events, creating an ordered categorical variable of frequency of self harm with seven categories defined as none, less than once per month, less than once per fortnight, less than once per week, once or more per week, twice or more per week, and most days. The treatment effect for the primary outcome was estimated using the proportional odds model. This model estimates the treatment effect as the odds ratio of a patient being in a category of more frequent self harm and allows adjustment for baseline covariates. These were treatment centre, sex, and baseline age, frequency, severity and risk of self harm, psychosocial risk, behavioural disorder, and depressive disorder as prespecified in the statistical analysis plan and approved by the trial steering committee. In view of the difficulties with the interpretation of the proportional odds ratio, which is greater than the corresponding rate ratio, we added an additional analysis related to the ratio of number of events between treatment arms. The ratio of the geometric mean number of days with deliberate self harm was approximated by $\log$ transforming the data for number of days using (1 + number of self harming events). As the transformed data were still strongly skewed we estimated confidence intervals using a non-parametric bootstrap.

Severity of self harm at follow-up, categorised as none, mild, moderate, and severe, was also analysed using a proportional odds model. This model estimates the treatment effect as the odds ratio of a patient being in a category of more frequent or more severe self harm and allows adjustment for baseline covariates, which were prespecified in the statistical analysis plan approved by the trial steering committee. Deliberate

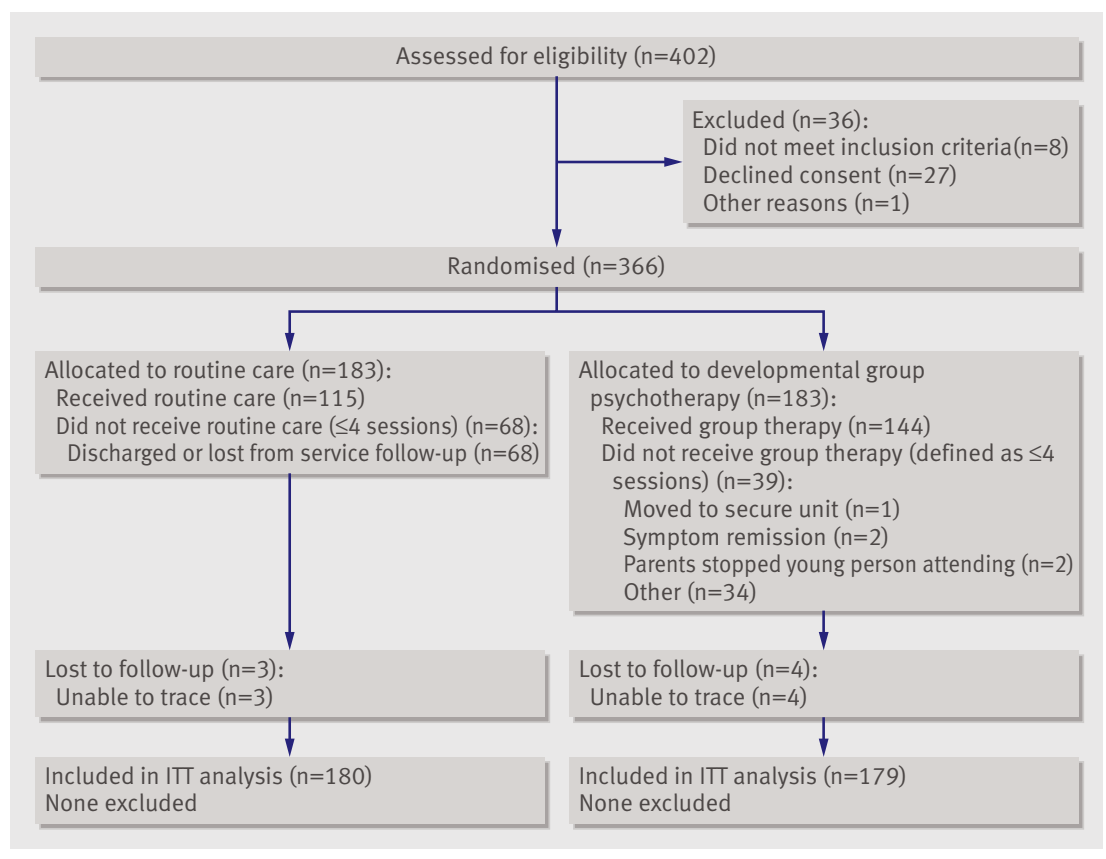

Fig 1 | ASSIST study profile. ITT=intention to treat self poisoning at follow-up was analysed using logistic regression. Other secondary outcome measures (scores on Moods and Feelings Questionnaire, Suicidal Ideation Questionnaire, Health of the Nation Outcome Scales for Children and Adolescents) $)^{303233}$ were analysed using analysis of covariance. The first repetition of self harm was modelled using a proportional hazards model. Three planned subgroup analyses were carried out to test for possible interaction between (1) antisocial symptoms, (2) depressive disorder, and (3) deliberate self poisoning for the primary outcome.

Total costs between groups at 12 months' follow-up were compared using standard $t$ tests, with ordinary least squares regression for adjusted analysis, and the results confirmed using non-parametric, bias corrected bootstrapping $^{54}$ in order to make inferences about the arithmetic mean. ${ }^{55}$ One way sensitivity analyses were undertaken to explore the sensitivity of the results to changes in assumptions: intervention costs were recalculated using the expected therapist salary scale for rollout into routine National Health Service practice (mid-point of the Agenda for Change grade 6); high cost outliers were excluded; parental travel costs and productivity losses were added to provide a broader cost perspective; and single imputation using multiple regression was used for missing cases.

Cost-effectiveness was explored at 12 months in terms of the proportion of young people who had not self harmed over the preceding six months, rather than the categorical primary outcome measure, frequency of self harm. Economic evaluation requires measures of effect with interval properties in order to draw conclusions about a move from one unit of effect to another. Categorical variables, where the interval between different categories is not meaningful or consistent, cannot support such an approach. Using a measure of the proportion of the population who had self harmed is also consistent with previous studies. ${ }^{56}$ Nonparametric bootstrapping from the costs and effectiveness data was used to generate a joint distribution of incremental mean costs and effects for group therapy and routine care. ${ }^{54}$ These distributions were used to calculate the probability that group therapy is the optimal choice, subject to a range of possible maximum values (ceiling ratio) that a decision maker might be willing to pay for a unit improvement in outcome. ${ }^{57}$ The ceiling ratio was varied to explore uncertainty in willingness to pay.

The study received ethical approval from the UK North West Multicentre Research Ethics Committee, ref 01-8-8.

\section{RESULTS}

\section{Participant flow}

The flow of participants through the study is outlined in figure 1. Eight centres participated and each contributed between 18 and 135 patients between August 2002 and August 2006. Follow-up analyses were done at a mean of 202 days (SD 33.5) and 377 days (SD 31.3) after randomisation. Pattern of recruitment and treatment by centre is shown in table 1 . 


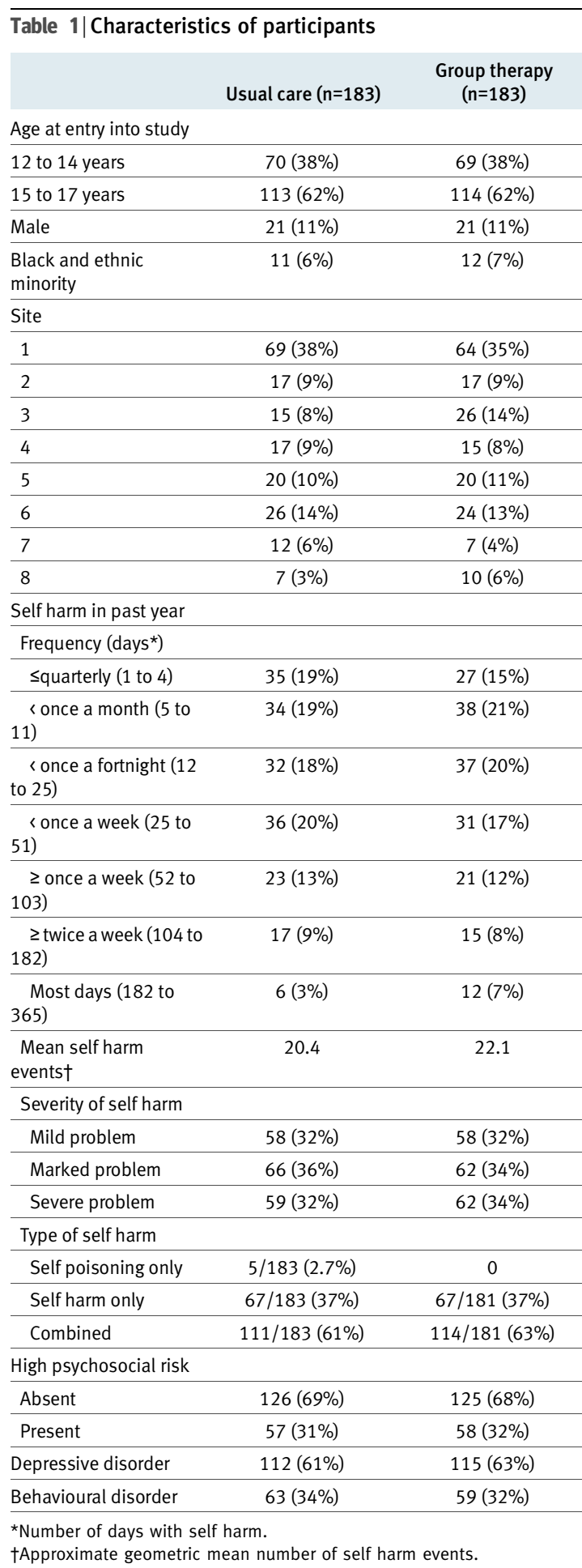

\section{Implementation of the intervention}

Developmental group psychotherapy was delivered per protocol in each treatment centre. Mean number of group sessions attended was 10.2 (SD 10.1): 144/183 $(79 \%)$ patients attended four or more sessions, the threshold set for treatment adherence (24/183 (6.7\%) attended no sessions, $56 / 183$ (15.7\%) 1-3 sessions, 112/ $183(31.5 \%)$ 4-11 sessions, 92/183 (25.8\%) 12-25 sessions, $72 / 183(20.2 \%) 26$ or more sessions). There was no evidence of systematic difference between session lengths or treatment frequency between participating centres (Kruskal-Wallis $\mathrm{P}=0.57$ ). Number of sessions of routine care was balanced well between trial arms, with a mean 9.7 (SD 10.4) sessions attended in the routine care arm and 8.5 (SD 11.2) sessions in the group therapy arm. The proportion of early dropout from routine care is typical in this clinical context; developmental group psychotherapy, however, showed significantly less early dropout (39/183 patients) than routine care $(68 / 183$ patients; $\mathrm{P}<0.0009$, fig 1).

\section{Baseline data}

Table 1 contains a summary of baseline data. The groups were well matched on key variables.

\section{Numbers analysed}

We substantially exceeded the target recruitment of $\mathrm{n}=312$ derived from the power calculation. For the primary outcome, we analysed data for 364 patients (group therapy 181, routine care 183) under intention to treat for frequency of self harm and 365 (group therapy 182 , routine care 183) for severity of self harm (table 2). Equivalent numbers for the other secondary outcomes are shown in table 3 .

\section{Outcomes and estimation \\ Primary outcome}

The cohort as a whole showed significant improvement from baseline to follow-up. At baseline 94/364 patients self harmed with a frequency of weekly or more often; at six months the proportion had fallen to $56 / 364$ and at one year to $28 / 364$ cases. At six months, $20 \%(75 / 362)$ showed no self harm and this increased to $40 \%(145 / 357)$ at one year. The proportion of patients defined as at "severe risk" (more than four episodes) fell from 33\% (121/365) at baseline to 13\% (46/ $365)$ at six months and $7 \%(24 / 365)$ at one year. Within this overall improvement, however, we noted no significant added advantage of group treatment over routine care. The proportional odds ratio of group therapy compared to routine care, adjusting for prespecified baseline variables (treatment centre, sex, age, frequency and severity of self harm risk, social impairment, level of behavioural disorder and depressive disorder) was 0.99 (CI 0.68 to $1.44, \mathrm{P}=0.95$ ) at six months and 0.88 ( 0.59 to $1.30, \mathrm{P}=0.52)$ at one year for frequency of self harm, which does not indicate a clinically important benefit, since neither confidence interval includes 0.5. The approximate ratio of the geometric means of group treatment compared with routine care was $1.01(95 \% \mathrm{CI} 0.80$ to $1.29, \mathrm{P}=0.91)$ at six months and 0.94 ( 0.73 to $1.18, \mathrm{P}=0.60)$ at 12 months. At neither point did the confidence interval include the third reduction in ratio of numbers of events between group therapy and routine care on which the power calculation was based. We therefore conclude that there is little evidence of additional benefit of group therapy over routine care. When a treatment allocation with site interaction was added to the 
Table 3 |Summary of secondary outcome measures by time point and treatment group

\begin{tabular}{|c|c|c|c|c|c|c|}
\hline & \multicolumn{2}{|c|}{ Routine care } & \multicolumn{2}{|c|}{ Group therapy } & \multicolumn{2}{|c|}{ Difference* } \\
\hline & Mean (SD), range & $\mathrm{n}$ & Mean (SD), range & $\mathrm{n}$ & Effect $(95 \% \mathrm{Cl})$ & $\mathbf{P}$ \\
\hline \multicolumn{7}{|l|}{ HoNOSCA $†$} \\
\hline Baseline & $16.8(5.8), 1-40$ & 183 & $17.5(5.7), 1-32$ & 181 & & \\
\hline 6 months & $12.6(6.1), 0-30$ & 180 & $12.2(6.3), 1-32$ & 172 & $-0.55(-1.64$ to 0.54$)$ & 0.32 \\
\hline 12 months & $11.7(6.7), 1-42$ & 178 & 10.9 (5.9), 0-26 & 168 & $-0.79(-1.98$ to 0.40$)$ & 0.19 \\
\hline \multicolumn{7}{|l|}{ MFQ† } \\
\hline Baseline & 38.6 (13.7), 1-61 & 179 & 41.0 (12.7), 4-62 & 175 & & \\
\hline 6 months & 27.6 (16.5), 0-60 & 178 & 28.5 (16.1), 0-60 & 171 & $-0.44(-3.49$ to 2.61$)$ & 0.78 \\
\hline 12 months & 24.6 (17.6), 0-62 & 174 & 24.4 (16.6), 0-61 & 170 & $-1.45(-4.90$ to 1.99$)$ & 0.41 \\
\hline \multicolumn{7}{|l|}{ SIQT } \\
\hline Baseline & 88.2 (45.5), 3-172 & 181 & 91.3 (42.8), 0-172 & 177 & & \\
\hline 6 months & 59.9 (48.4), 0-174 & 179 & 61.5 (45.5), 0-165 & 171 & $0.07(-8.60$ to 8.75$)$ & 0.99 \\
\hline 12 months & 49.2 (46.8), 0-179 & 174 & 48.3 (42.7), 0-165 & 169 & $-2.37(-11.11$ to 6.36$)$ & 0.59 \\
\hline \multicolumn{7}{|c|}{$\begin{array}{l}\text { *Mean difference between group and usual care adjusted for treatment centre, sex, baseline age, frequency and severity of self-harm, psychosocia } \\
\text { risk, behavioural disorder, and depressive disorder. } \\
\text { †Health of the Nation Outcome Scales for Children and Adolescents ranges from } 0 \text { to } 52 \text {, greater score indicates greater impairment. Mood and } \\
\text { Feelings Questionnaire ranges from } 0 \text { to } 64 \text {; greater score indicates greater symptom severity; clinical diagnostic cut off } 28 / 9 \text {. Suicidal Ideation } \\
\text { Questionnaire ranges from } 0 \text { to } 180 ; \text { score }>40 \text { indicates substantial suicidal ideation. }\end{array}$} \\
\hline
\end{tabular}

Table 2 | Frequency and severity of self harm at baseline and follow-up
\[ \begin{array}{l}0-6 \text { months } \\ \text { Routine care Group therapy }\end{array} \]

Frequency

\begin{tabular}{lllll}
\hline $\mathrm{n}$ & $\mathrm{n}=181$ & $\mathrm{n}=181$ & $\mathrm{n}=180$ & $\mathrm{n}=179$ \\
\hline
\end{tabular}

Number of days of self

harm during the period

\begin{tabular}{|c|c|c|c|c|}
\hline 0 (none) & $39(21.5,100.0)$ & $36(19.9,100.0)$ & $70(38.9,100.0)$ & $75(41.9,100.0)$ \\
\hline $1-2(\leq$ quarterly $)$ & $42(23.2,78.5)$ & $45(24.9,80.1)$ & $46(25.6,61.1)$ & $36(20.1,58.1)$ \\
\hline 3-5 (sonce a month) & $28(15.5,55.2)$ & $22(12.2,55.2)$ & $21(11.7,35.6)$ & $21(11.7,38.0)$ \\
\hline 6-12 ( 1 a fortnight) & $26(14.4,39.8)$ & $33(18.2,43.1)$ & $16(8.9,23.9)$ & $22(12.3,26.3)$ \\
\hline 13-25 (ıonce a week) & $19(10.5,25.4)$ & $16(8.8,24.9)$ & $11(6.1,15.0)$ & $13(7.3,14.0)$ \\
\hline $\begin{array}{l}26-51 \text { ( } \geq \text { once a } \\
\text { week) }\end{array}$ & $13(7.2,14.9)$ & $13(7.2,16.0)$ & $10(5.6,8.9)$ & $4(2.2,6.7)$ \\
\hline $\begin{array}{l}\text { 52-91 ( } \geq \text { twice a } \\
\text { week) }\end{array}$ & $9(5.0,7.7)$ & $11(6.1,8.8)$ & $3(1.7,3.3)$ & $4(2.2,4.5)$ \\
\hline 92-182 (most days) & $5(2.8,2.8)$ & $5(2.8,2.8)$ & $3(1.7,1.7)$ & $4(2.2,2.2)$ \\
\hline Approximate & 4.4 & 4.6 & 2.1 & 2.0 \\
\hline
\end{tabular}

geometric mean

number of self harm

events

\begin{tabular}{lcc}
\hline $\begin{array}{l}\text { Proportional odds } \\
\text { ratio* }(95 \% \mathrm{Cl}), \mathrm{P}\end{array}$ & $0.99(0.68$ to 1.44$)$, & 0.88 (0.59 to 1.30$),$ \\
$\mathrm{P}=0.52$
\end{tabular}

\section{Severity}

\begin{tabular}{lcccc} 
& $\mathrm{n}=181$ & $\mathrm{n}=181$ & $\mathrm{n}=180$ & \\
\hline No problem & $40(22.1,100.0)$ & $37(20.4,100.0)$ & $70(38.9,100.0)$ & $75(42.1,100.0)$
\end{tabular}

Mild problem $\quad 79(43.7,77.9) \quad 96(53.0,79.6) \quad 76(42.2,61.1) \quad 68(38.2,57.9)$

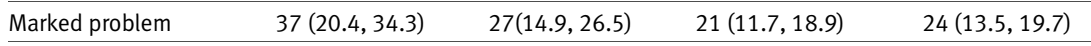

\begin{tabular}{lllll}
\hline Severe problem & $25(13.8,13.8)$ & $21(11.6,11.6)$ & $13(7.2,7.2)$ & $11(6.2,6.2)$
\end{tabular}

Proportional odds $\quad 0.81$ (0.54 to 1.20$), \quad 0.94$ (0.63 to 1.40$)$,

$\begin{array}{rr}\text { ratio * }(95 \% \mathrm{Cl}), \mathrm{P} & \mathrm{P}=0.29 \quad \mathrm{P}=0.75\end{array}$

Data are frequency (\%, \% greater than or equal to each level) unless otherwise stated.

* Proportional odds ratio of group therapy compared with routine care adjusted for treatment centre, sex, baseline age, frequency and

severity of self harm, harm risk, psychosocial risk, behavioural disorder, and depressive disorder. Values below 1 represent a less adverse outcome for group therapy compared with routine care.

†Ratio of geometric mean numbers of events for group therapy compared with routine care adjusted for treatment centre, sex, baseline age, frequency, severity, and risk of self harm, psychosocial risk, behavioural disorder, and depressive disorder. Values below 1 represent a less adverse outcome for group therapy compared with routine care. models there was no evidence of variation in the treatment effect between sites for self harm frequency and severity.

The median time to the first repetition of self harm post-randomisation in the group treatment arm was 37 days (interquartile range 15 to 123 days) and in the routine care arm 49 days (17 to 184 days); hazard ratio 1.07 (95\% CI 0.85 to $1.34, \mathrm{P}=0.58)$.

\section{Secondary outcomes}

For severity of self harm, the proportional odds ratio of group therapy compared with routine care adjusting for pre-specified baseline variables was 0.81 (95\% CI 0.54 to $1.20, \mathrm{P}=0.29)$ at six months and 0.94 (0.63 to 40 , $\mathrm{P}=0.75)$ at one year. At baseline 63\% (230/364) of patients were self poisoning. By six months this proportion had reduced substantially; 25\% (45/181) receiving group therapy had self poisoned compared with $27 \%(48 / 181)$ in the routine care arm (adjusted odds ratio $0.80,95 \%$ CI 0.48 to $1.35, \mathrm{P}=0.41)$. At 12 months $16 \%(28 / 179)$ receiving group therapy had self poisoned compared with 15\% (27/180) in the routine care arm (adjusted odds ratio $0.97,95 \%$ CI 0.53 to $1.77, \mathrm{P}=0.92)$.

On other secondary measures there was also an overall cohort improvement through the trial. Mood, suicidality, and social functioning improved (Mood and Feelings Questionnaire by 14 points in usual care and 16.6 points in group treatment; Suicidal Ideation Questionnaire by 33 points in usual care, 43 points in group treatment; Health of the Nation Outcome Scales for Children and Adolescents score dropping by mean 5 points in usual care and 6.6 points in group treatment). There was however no significant relative difference in improvement between the groups (adjusted treatment effect for Mood and Feelings Questionnaire -1.45 , Suicidal Ideation Questionnaire -2.37, Health of the Nation Outcome Scales for Children and Adolescents -0.79 ; all non-significant). 


\section{Subgroup analyses}

In the absence of any difference between treatments overall, a differential effect of the intervention according to a baseline characteristics requires a qualitative interaction. Pre-specified subgroup analyses considered three factors: antisocial symptoms, depressive disorder, and deliberate self poisoning before the trial. As summarised in table 4 , there was no evidence of a differential treatment effect for the frequency and severity of self harm at follow-up on any of the three factors.

\section{Economic evaluation}

Full resource use data were available for 304 young people ( $83 \%$ of randomised cases); 151 in group therapy and 153 in routine care. Resource use, reported in table 5, was similar between groups. Most of the study participants lived at home with their families for some period over follow-up; however a substantial proportion spent time living independently, in the care of social services (foster or residential care), or in temporary accommodation such as shelters and hostels. Those receiving developmental group psychotherapy spent considerably more time in residential care than the routine care group (mean 20 versus eight days). Time spent in secure care/youth offending institutions was also slightly higher for group therapy (mean one versus no days).

There was no evidence that developmental group psychotherapy resulted in any reduction or increase

\begin{tabular}{|c|c|c|}
\hline & $\begin{array}{l}\text { Ratio of proportional } \\
\text { odds ratios* }(95 \% \mathrm{Cl})\end{array}$ & $\mathbf{P}$ \\
\hline \multicolumn{3}{|c|}{ Antisocial symptoms } \\
\hline \multicolumn{3}{|l|}{ Frequency } \\
\hline 6 months & $0.86(0.30$ to 2.45$)$ & 0.78 \\
\hline 12 months & 0.73 (0.26 to 2.09$)$ & 0.56 \\
\hline \multicolumn{3}{|l|}{ Severity } \\
\hline 6 months & $1.43(0.48$ to 4.20$)$ & 0.52 \\
\hline 12 months & 0.42 (0.14 to 1.28$)$ & 0.13 \\
\hline \multicolumn{3}{|c|}{ Depressive disorder } \\
\hline \multicolumn{3}{|l|}{ Frequency } \\
\hline 6 months & 0.97 (0.44 to 2.15$)$ & 0.94 \\
\hline 12 months & 0.91 (0.39 to 2.12$)$ & 0.83 \\
\hline \multicolumn{3}{|l|}{ Severity } \\
\hline 6 months & 0.71 (0.31 to 1.61$)$ & 0.41 \\
\hline 12 months & $1.00(0.43$ to 2.33$)$ & 1.00 \\
\hline \multicolumn{3}{|c|}{ Deliberate self poisoning } \\
\hline \multicolumn{3}{|l|}{ Frequency } \\
\hline 6 months & $1.18(0.48$ to 0.39$)$ & 0.69 \\
\hline 12 months & $1.09(0.46$ to 0.20$)$ & 0.85 \\
\hline \multicolumn{3}{|l|}{ Severity } \\
\hline 6 months & 1.03 (0.44 to 0.08$)$ & 0.94 \\
\hline 12 months & $0.90(0.38$ to 0.26$)$ & 0.80 \\
\hline \multicolumn{3}{|c|}{$\begin{array}{l}\text { * Ratio of proportional odds ratios for the treatment effect adjusting for } \\
\text { centre, sex, baseline age, severity of self harm, psychosocial risk, } \\
\text { behavioural disorder, and depressive disorder, comparing factor present } \\
\text { with factor absent. Ratio equal to } 1 \text { represents no treatment with factor } \\
\text { interaction. }\end{array}$} \\
\hline
\end{tabular}

in health service use. Accident and emergency services were used by almost half of the group. Around a third of the group spent at least one night as an inpatient. Almost all the young people in the study had at least one contact with their local Child and Adolescent Mental Health Services team or another outpatient appointment, and the average number of appointments was 11 . Primary care and social work contacts were also relatively common. Few were admitted to inpatient psychiatric care, but when they were, it was for long periods of time.

Total costs per young person are reported in table 6 . Total costs per young person were higher for developmental group psychotherapy ( $£ 21781$ [€25 232, \$ $35282])$ than routine care (£15 372), but this difference was not significant $(95 \%$ CI -1416 to $10782, \mathrm{P}=0.132)$. Results from the bootstrapped analyses were very similar and so are not reported here. There was a trend for total costs per young person to increase over the first six months following randomisation, then to fall below baseline levels over the second six months of followup. Figure 2 demonstrates the skewed nature of the cost data with a small number of very costly young people in both groups. Results of the sensitivity analyses reported in table 6 , suggest that the approach used in the economic evaluation was robust to changes in assumptions.

At 12 months' follow-up, using the full sample including imputation for missing cases, the proportion of participants who had not harmed themselves over the preceding six months was slightly higher for the group therapy $(41.9 \%)$ than for routine care $(38.9 \%$, table 2). Thus, the group therapy generated small improvements in outcomes for large increases in costs. The incremental cost-effectiveness of the group therapy was $£ 2020$ per $1 \%$ increase in the proportion of young people not self harming. The probability that group therapy is more cost-effective than routine care ranges from $12 \%$ to a maximum of only $28 \%$ as willingness to pay for improvements in outcome increases.

\section{Adverse events}

Three instances of significant adverse events were reported during the trial period; all involved self harm resulting in severe physical injury. Two of the patients involved were in treatment as usual and one in the experimental arm. No completed suicide or other death was recorded during the trial.

\section{DISCUSSION}

This is one of the largest randomised trials undertaken internationally targeting self harm in adolescents or at any age. We evaluated the effectiveness of adding a manual based group treatment, developmental group psychotherapy, for adolescents presenting with repeated self harm to routine treatment compared with routine care alone. The majority of patients in our study were young people self harming with or without self poisoning rather than with self poisoning alone. The results show an overall improvement in functioning over the study period across the whole cohort. The 
addition of group treatment did not significantly further improve measured primary or secondary outcomes. Nor did it reduce the range, extent, or cost of treatment as usual: indeed the addition of developmental group psychotherapy to routine care was associated with a trend to higher costs over 12 months' follow-up (largely owing to two individuals in developmental group psychotherapy who spent substantial time in hospital or in the care of social services over followup-their exclusion in sensitivity analysis did not alter the main findings of the study). Developmental group psychotherapy is therefore not, according to this evidence, a cost-effective addition to the routine care delivered, and this conclusion held for all values that a decision maker might be willing to pay for improvements in outcomes.

The strengths of the study lie in the sample size (we substantially over-recruited against the target for power, owing to the high follow-up rate that was achieved); in the careful attention to blinding and reducing assessment bias; in the very low rate of attrition to end point in a complex group of young people; the detailed ascertainment of usual treatment; and the broad economic perspective taken. The experimental intervention was an open group design adapted to the needs of the young people. This proved pragmatic in practice and well accepted by young people, families, and Child and Adolescent Mental Health Service teams. There has been substantial demand from teams to continue the group service locally after the trial closure, suggesting that the intervention is suitable for practice within the UK National Health Service.

These findings are at variance with the initial pilot study of developmental group psychotherapy ${ }^{25}$ but in line with a subsequent replication conducted by Hazell and colleagues. ${ }^{26}$ Some of the differences in the results may come from comparative sample complexity at baseline in this study and the intervening evolution of the routine Child and Adolescent Mental Health Service treatment for self harm. The initial pilot study ${ }^{25}$ took place in a single district Child and Adolescent Mental Health Service, whereas the subsequent replication ${ }^{26}$ and the current study used wider referral samples (in the current case from a catchment of approximately five million); referrals tended towards high baseline severity, complexity, and chronicity. A related feature of this study was the very high level of continuing use of Child and Adolescent Mental Health Services in the year to follow-up (in 86\% of the cohort, with a relatively high frequency of appointments). In addition, over a quarter of the sample had contact with a community psychiatric nurse and there was extensive use of general practitioner (in 77\% of the sample) and voluntary sector (in $20 \%$ of the sample) services. This high use of health resources suggests that, in the geographical area of the study at least, these young people receive a significant amount of ongoing help-a pattern that replicates the recent Australian findings and may also reflect the cumulative impact of research and service development around adolescent self harm in the trial area in recent years. A limitation to inferences
Table 5| Service use over follow-up.

\begin{tabular}{|c|c|c|c|c|}
\hline \multirow[b]{2}{*}{ Service (unit) } & \multicolumn{2}{|c|}{$\begin{array}{l}\text { Routine care } \\
\qquad(n=153)\end{array}$} & \multicolumn{2}{|c|}{$\begin{array}{l}\text { Group therapy } \\
\quad(n=151)\end{array}$} \\
\hline & Mean (SD) & $\%$ & Mean (SD) & $\%$ \\
\hline \multicolumn{5}{|l|}{ Accommodation } \\
\hline $\begin{array}{l}\text { Living with family } \\
\text { (nights) }\end{array}$ & $\begin{array}{l}347.1 \\
(74.6)\end{array}$ & 98 & $\begin{array}{c}326.5 \\
(109.9)\end{array}$ & 93 \\
\hline $\begin{array}{l}\text { Independent living } \\
\text { (nights) }\end{array}$ & $5.2(37.1)$ & 3 & $0.8(8.3)$ & 1 \\
\hline Foster care (nights) & $1.5(16.1)$ & 2 & $4.0(30.1)$ & 2 \\
\hline $\begin{array}{l}\text { Residential care } \\
\text { (nights) }\end{array}$ & $7.8(43.7)$ & 5 & $20.0(73.3)$ & 8 \\
\hline $\begin{array}{l}\text { Shelter/refuge } \\
\text { (nights) }\end{array}$ & $3.0(19.3)$ & 3 & $6.0(34.7)$ & 3 \\
\hline $\begin{array}{l}\text { Bed and breakfast/ } \\
\text { hotel (nights) }\end{array}$ & $0.2(2.3)$ & 1 & $0.0(0.0)$ & 0 \\
\hline
\end{tabular}

Hospital services

$\begin{array}{lllll}\text { Inpatient psychiatric } & 9.0(29.1) & 12 & 11.6(42.0) & 17\end{array}$

(days)

\begin{tabular}{lcccc}
\hline $\begin{array}{c}\text { Inpatient medical } \\
\text { (days) }\end{array}$ & $2.2(9.3)$ & 26 & $1.2(3.3)$ & 26 \\
\hline $\begin{array}{c}\text { CAMHS/outpatient } \\
\text { (appointments) }\end{array}$ & $9.5(13.2)$ & 89 & $12.8(20.7)$ & 83 \\
\hline $\begin{array}{c}\text { Day patient } \\
\text { (appointments) }\end{array}$ & $2.8(17.6)$ & 11 & $0.4(1.7)$ & 10 \\
\hline $\begin{array}{c}\text { Accident and } \\
\text { emergency }\end{array}$ & $1.0(1.7)$ & 48 & $1.3(2.9)$ & 49
\end{tabular}

(attendances)

Community health and

social services

\begin{tabular}{lllll}
$\begin{array}{c}\text { General practitioner } \\
\text { (contact) }\end{array}$ & $3.0(3.5)$ & 76 & $3.1(3.5)$ & 78 \\
\hline $\begin{array}{c}\text { Practice nurse } \\
\text { (contact) }\end{array}$ & $0.4(0.9)$ & 19 & $0.5(2.0)$ & 15 \\
\hline Community & $3.8(10.1)$ & 28 & $2.6(7.7)$ & 28
\end{tabular}

psychiatric nurse

(contact)

\begin{tabular}{lllll}
\hline $\begin{array}{c}\text { Health visitor } \\
\text { (contact) }\end{array}$ & $1.7(8.8)$ & 6 & $0.2(1.9)$ & 2 \\
\hline Psychologist (contact) & $0.4(2.0)$ & 6 & $0.1(1.6)$ & 1 \\
\hline Counsellor (contact) & $0.4(4.2)$ & 2 & $0.1(0.4)$ & 2 \\
\hline $\begin{array}{c}\text { Family therapist } \\
\text { (contact) }\end{array}$ & $0.2(1.0)$ & 4 & $0.1(0.5)$ & 2 \\
\hline $\begin{array}{c}\text { Drug and alcohol } \\
\text { worker (contact) }\end{array}$ & $0.1(1.1)$ & 1 & $0.5(3.8)$ & 2 \\
\hline $\begin{array}{c}\text { Dietitian (contact) } \\
\text { Family planning }\end{array}$ & $0.0(0.2)$ & 1 & $0.0(0.0)$ & 0 \\
\hline \begin{tabular}{c} 
service (contact) \\
\hline $\begin{array}{c}\text { Physiotherapist } \\
\text { (contact) }\end{array}$
\end{tabular} & $0.0(0.1)$ & 1 & $0.0(0.1)$ & 1 \\
\hline $\begin{array}{c}\text { Occupational } \\
\text { therapist (contact) }\end{array}$ & $0.0(0.0)$ & 0 & $0.1(1.8)$ & 1 \\
\hline $\begin{array}{c}\text { Walk-in centre } \\
\text { (attendances) }\end{array}$ & $0.0(0.2)$ & 1 & $0.0(0.2)$ & 1 \\
\hline $\begin{array}{c}\text { Social worker } \\
\text { (contact) }\end{array}$ & $2.0(4.8)$ & 33 & $2.4(6.4)$ & 25 \\
\hline $\begin{array}{c}\text { Support worker } \\
\text { (contact) }\end{array}$ & $1.5(6.2)$ & 11 & $1.8(7.4)$ & 11 \\
\hline $\begin{array}{c}\text { School doctor } \\
\text { contact) }\end{array}$ & $0.0(0.1)$ & 1 & $0.0(0.0)$ & 0 \\
\hline $\begin{array}{c}\text { School nurse } \\
\text { (contact) }\end{array}$ & $1.2(6.1)$ & 14 & $0.2(0.9)$ & 6 \\
\hline $\begin{array}{c}\text { Voluntary sector } \\
\text { services (contacts) }\end{array}$ & $19.4)$ & $1.8(5.6)$ & 20 \\
\hline $\begin{array}{l}\text { Education/education } \\
\text { services }\end{array}$ & $0.2)$ & \\
\hline
\end{tabular}




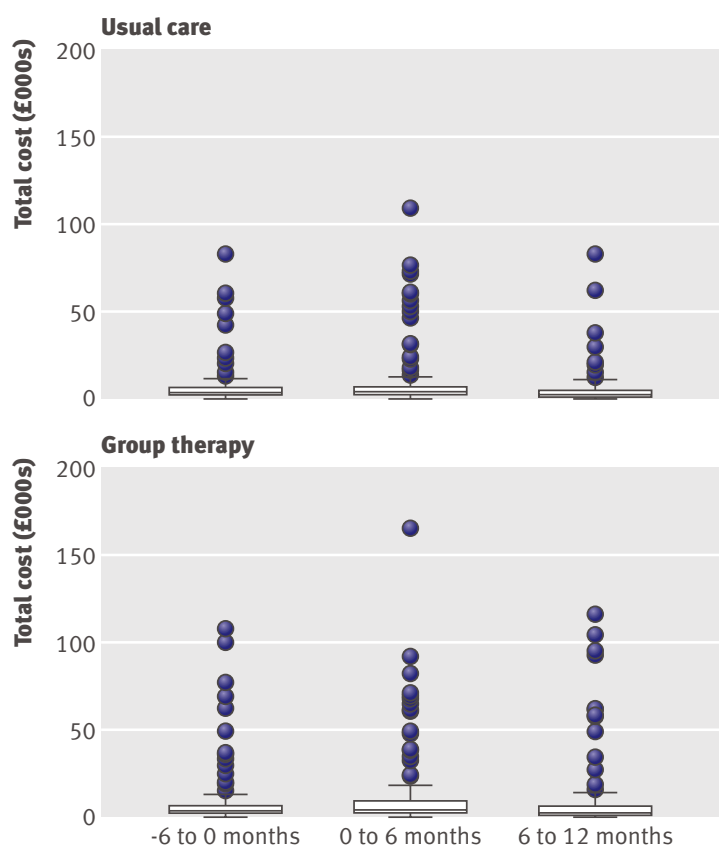

Fig 2| Box and whisker plot of total cost per participant prebaseline, 6 months, and 12 months from baseline by randomised group $(£)$

from this trial is that we cannot know whether this high level of service use would generalise to other child and adolescent mental health service contexts.

The design of the trial did not allow testing between explanatory hypotheses about the cause of the overall cohort improvement; whether, for instance, it was related to a regression to the mean or to a rather better natural history of adolescent self harm than is often supposed. Few long term follow-up studies of adolescent self harm have been done, with most studies concentrating on specific short outcomes on suicide and repetition. Harrington and colleagues ${ }^{19}$ followed up a sample of patients who participated in a family therapy intervention after a single overdose compared with matched controls identified through general practitioner surgeries, and found that $70 \%$ were no longer self harming at three years but $50 \%$ had used adult mental health services. Studies in older age groups suggest that the prevalence of self harm may decrease after 18 years $^{58}$ and our results suggest this decrease may begin before this age. Alternatively, the overall improvement could relate to the considerable amount of routine ascertainment and care demonstrated in both arms in this sample; studies of adult self harm have suggested that even a small amount of contact, for instance with postcards, can help prevent repetition in some individual $s^{59}$-although overall evidence for this is also mixed. ${ }^{60}$

The evidence from the trial does not therefore lend support to the addition of developmental group psychotherapy to current routine care for the Child and Adolescent Mental Health Services treatment of adolescent self harm. However, the detailed evaluation of service use does highlight the potential effect of a range

\begin{tabular}{|c|c|c|c|c|}
\hline \multirow[b]{2}{*}{ Service (unit) } & \multicolumn{2}{|c|}{$\begin{array}{l}\text { Routine care } \\
(n=153)\end{array}$} & \multicolumn{2}{|c|}{$\begin{array}{l}\text { Group therapy } \\
\quad(n=151)\end{array}$} \\
\hline & Mean (SD) & $\%$ & Mean (SD) & $\%$ \\
\hline $\begin{array}{l}\text { Mainstream school } \\
\text { (months) }\end{array}$ & $7.1(5.1)$ & 62 & $6.0(5.0)$ & 66 \\
\hline $\begin{array}{l}\text { Private day school } \\
\text { (months) }\end{array}$ & $0.3(1.5)$ & 3 & $0.4(1.9)$ & 5 \\
\hline College (months) & $1.4(2.8)$ & 23 & $1.2(2.5)$ & 22 \\
\hline $\begin{array}{l}\text { Residential school } \\
\text { (months) }\end{array}$ & $0.0(0.0)$ & 0 & $0.2(1.1)$ & 3 \\
\hline $\begin{array}{l}\text { LD/EBD school } \\
\text { (months) }\end{array}$ & $0.1(1.0)$ & 1 & $0.0(0.5)$ & 1 \\
\hline $\begin{array}{l}\text { Pupil referral unit } \\
\text { (months) }\end{array}$ & $0.6(2.2)$ & 8 & $0.4(1.8)$ & 6 \\
\hline $\begin{array}{l}\text { Hospital school } \\
\text { (months) }\end{array}$ & $0.6(2.1)$ & 8 & $0.8(2.5)$ & 11 \\
\hline $\begin{array}{l}\text { Home tuition } \\
\text { (months) }\end{array}$ & $0.1(0.4)$ & 3 & $0.1(0.8)$ & 3 \\
\hline $\begin{array}{l}\text { Classroom support } \\
\text { (sessions) }\end{array}$ & $0.9(9.7)$ & 2 & $0.1(0.7)$ & 1 \\
\hline $\begin{array}{l}\text { Education welfare } \\
\text { officer (contact) }\end{array}$ & $0.2(0.8)$ & 9 & $0.3(2.3)$ & 5 \\
\hline $\begin{array}{l}\text { Education } \\
\text { psychologist (contact) }\end{array}$ & $0.0(0.4)$ & 2 & $0.1(0.7)$ & 1 \\
\hline $\begin{array}{l}\text { Education counsellor } \\
\text { (contact) }\end{array}$ & $0.5(2.7)$ & 6 & $1.1(6.2)$ & 6 \\
\hline Mentor (contact) & $3.4(15.1)$ & 12 & $2.3(11.2)$ & 8 \\
\hline Connexions (contact) & $1.4(4.5)$ & 22 & $0.8(2.1)$ & 18 \\
\hline \multicolumn{5}{|l|}{ Criminal justice } \\
\hline $\begin{array}{l}\text { Youth offending team } \\
\text { (contact) }\end{array}$ & $0.6(2.7)$ & 7 & $0.9(4.0)$ & 9 \\
\hline Solicitor (contact) & $0.3(1.7)$ & 5 & $0.1(0.8)$ & 4 \\
\hline Police (contact) & $1.6(6.8)$ & 37 & $1.8(5.3)$ & 37 \\
\hline Court (contact) & $0.3(2.0)$ & 6 & $0.4(2.4)$ & 6 \\
\hline $\begin{array}{l}\text { Secure care/young } \\
\text { offenders' institute } \\
\text { (nights) }\end{array}$ & $0.0(0.0)$ & 0 & $0.9(8.3)$ & 2 \\
\hline $\begin{array}{l}\text { Police custody/ } \\
\text { remand (sessions) }\end{array}$ & $0.1(0.7)$ & 1 & $0.1(1.2)$ & 2 \\
\hline
\end{tabular}

CAMHS=child and adolescent mental health services. $L D / E B D=$ learning difficulties/emotional and behavioural difficulties.

of current services on self harm, and raises questions as to which of these are most effective. Follow-up of this well characterised cohort would add useful information about the natural history of repeated self harming behaviour in adolescence; comparative studies in areas with different patterns of service use would illuminate the potential effect of routine care in this study. Self harm in adolescence remains a very challenging public health problem that deserves continuing research and clinical efforts towards its alleviation.

We thank all the participating teams that contributed to referrals and interventions. We particularly acknowledge the involvement of the young people and their families at a difficult time in their lives. Professor Dick Harrington inspired and led this study before his untimely death in 2004. We are grateful for the support of the Trial Steering Committee (Simon Gowers (chair), Sally Hollis, Andy Clarke, Ian McKinnon).

Contributors: $\mathrm{RH}, \mathrm{AJW}, \mathrm{MK}, \mathrm{GT}, \mathrm{SB}$, and CR initially conceived and designed the study. JR, EA, AW, BB, and JG contributed to the design and analysis plan. AW and GT led the therapy delivery and supervision. JG led the trial following the death of Richard Harrington and the retirement of Mike Kerfoot. CR prepared the statistical analysis plan and undertook the statistical analysis. All authors contributed to the interpretation of the data. JG led the drafting of the article. All authors contributed to the revision of the article and gave final approval of the manuscript. JJG is the 


\section{WHAT THIS PAPER ADDS}

\section{What is already known}

Self harm is a major public health problem in many countries but uncertainty remains about which forms of treatment are most effective.

Studies to date have been methodologically limited and few have specifically assessed self harm in adolescents

\section{What this study adds}

We identified substantial involvement of mental health and primary care services in care for patients who self harmed in the geographical area of the study, along with a considerable symptom improvement across both arms of the trial at one year's follow-up.

guarantor of the study and made the final decision to submit. All authors had full access to all of the data (including statistical reports and tables) in the study and take responsibility for the integrity of the data and the accuracy of the data analysis.

Funding: The study was funded by the Health Foundation and sponsored by the University of Manchester. Neither funder nor sponsor had any role in the design, data collection, interpretation, or write up of the study. All researchers in the study were independent of the funding body. Competing interest statement: All authors have completed the Unified Competing Interest form at www.icmje.org/coi_disclosure.pdf (available on request from the corresponding author) and declare: no support from any organisation for the submitted work; no financial relationships with any organisations that might have an interest in the submitted work in the previous three years; no other relationships or activities that could appear to have influenced the submitted work.

Data sharing: Technical appendix, statistical code, and dataset available from the corresponding author at jonathan.green@manchester.ac.uk. Participant consent was not obtained but the presented data are anonymised and risk of identification is low.

1 National Collaborating Centre for Mental Health. Full guideline. Selfharm: the short-term physical and psychological management and secondary prevention of self-harm in primary and secondary care. 2004. www.nice.org.uk/CG016.

2 Hawton K, Houston K, Shepperd R. Suicide in young people: study of 174 cases, aged under 25 years, based on coroners' and medical records. Br J Psychiatry 1999;175:271-6.

3 Fergusson DM, Lynskey MT. Suicide attempts and suicidal ideation in birth cohort of 16 year old New Zealanders. J Am Acad Child Adolesc Psychiatry 1995;34:1308-17.

4 Brent DA, Johnson B, Bartle S, Bridge J, Rather C, Matha J, et al. Personality disorder, tendency to impulsive violence, and suicidal behaviour in adolescents. I Am Acad Child Adolesc Psychiatry 1993a;32:69-75.

5 Brent DA, Holder D, Kolko D, Birmaher B, Baugher M, Roth C, et al. Clinical psychotherapy trial for adolescent depression comparing cognitive, family, and supportive therapy. Arch Gen Psychiatry 1997;54:877-5.

6 Hawton K, Fagg J, Platt S, Hawkins M. Factors associated with suicide after parasuicide in young people. BMJ 1993;306:1641-4.

7 Hummel P, Poggenburg I, Specht F, Thomke V. Repeated suicide attempts by children and adolescents: results of a retrospective study. Klin Padiatr 2000;212:268-72.

8 Granboulan V, Rabain D, Basquin M. The outcomes of adolescent suicide attempts. Acta Psychiatr Scand 1995;91:265-70.

9 Vajda J, Steinbeck K. Factors associated with repeat suicide attempts among adolescents. Aust N ZJ Psychiatry 2000;34:437-45.

10 Beautrais AL. Serious suicide attempts in young people: a case control study. [Dissertation.] University of Ottago, 1996.

11 Brent DA, Perper JA, Moritz G, Allman C, Roth C, Schweers J, et al. Psychiatric risk factors of adolescent suicide: a case-control study. Am Acad Child Adolesc Psychiatry 1993b;32:521-9.

12 Kerfoot M. Suicide and deliberate self-harm in children and adolescents: a research update. Children Soc 1996;10:236-41.

13 Beautrais AL, Joyce PR, Mulder RT. Psychiatric illness in a New Zealand sample of young people making serious suicide attempts. $N$ Z Med J 1998;111:44-8.

14 Burgess S, Hawton K, Loveday G. Adolescents who take overdoses: outcome in terms of changes in psychopathology and the adolescents' attitudes to care and to their overdose. J Adolesc 1998;21:209-18.

15 Harrington RC, Kerfoot M, Dyer E, McNiven F, Gill J, Harrington V, et al. Randomised trial of a home-based intervention for children who
Table $6 \mid$ Total cost per young person over 12 months' followup

\begin{tabular}{|c|c|c|c|c|}
\hline & \multicolumn{2}{|c|}{ Mean (SD) cost $(£)^{\star}$} & \multirow{2}{*}{$\begin{array}{c}\text { Mean } \\
\text { difference } \\
(95 \% \mathrm{Cl})\end{array}$} & \multirow[b]{2}{*}{$\mathrm{P} \dagger$} \\
\hline & $\begin{array}{l}\text { Routine care } \\
\qquad(n=153)\end{array}$ & $\begin{array}{l}\text { Group } \\
\text { therapy } \\
(n=151)\end{array}$ & & \\
\hline Health services & $\begin{array}{c}8058(16 \\
615)\end{array}$ & $\begin{array}{c}9138(22 \\
373)\end{array}$ & $\begin{array}{c}-1080 \\
(-3364 \text { to } \\
5523)\end{array}$ & \\
\hline Intervention & $47(271)$ & 207 (325) & & \\
\hline $\begin{array}{l}\text { Hospital } \\
\text { services }\end{array}$ & $\begin{array}{c}7549(16 \\
260)\end{array}$ & $\begin{array}{c}8549(22 \\
138)\end{array}$ & & \\
\hline $\begin{array}{l}\text { Community } \\
\text { health services }\end{array}$ & $350(690)$ & 304 (862) & & \\
\hline Medication & $113(461)$ & $78(266)$ & & \\
\hline Social services & $\begin{array}{c}3119(15 \\
007)\end{array}$ & $\begin{array}{c}7412(24 \\
384)\end{array}$ & $\begin{array}{c}-4293 \\
(-8856 \text { to } \\
271)\end{array}$ & \\
\hline $\begin{array}{l}\text { Voluntary } \\
\text { sector services }\end{array}$ & $59(281)$ & $48(173)$ & $\begin{array}{c}-11(-42 \text { to } \\
64)\end{array}$ & \\
\hline $\begin{array}{l}\text { Education/ } \\
\text { education } \\
\text { services }\end{array}$ & 3940 (3 438) & 3957 (3615) & $\begin{array}{c}-17(-814 \text { to } \\
779)\end{array}$ & \\
\hline $\begin{array}{l}\text { Criminal } \\
\text { justice sector } \\
\text { services }\end{array}$ & $196(738)$ & 1225 (8301) & $\begin{array}{c}-1029 \\
(-2355 \text { to } \\
297)\end{array}$ & \\
\hline Total cost & $\begin{array}{c}15372(24 \\
981)\end{array}$ & $\begin{array}{c}21781(38 \\
794)\end{array}$ & $\begin{array}{l}-6408(-13 \\
763 \text { to } 947)\end{array}$ & 0.132 \\
\hline $\begin{array}{l}\text { Likely } \\
\text { intervention } \\
\text { rollout costs } \\
(n=304)\end{array}$ & $\begin{array}{c}15354(24 \\
944)\end{array}$ & $\begin{array}{c}21739(38 \\
772)\end{array}$ & $\begin{array}{l}-6383(-13 \\
732 \text { to } 965)\end{array}$ & 0.134 \\
\hline $\begin{array}{l}\text { Excluding two } \\
\text { high cost } \\
\text { outliers } \\
(n=302)\end{array}$ & $\begin{array}{c}15372(24 \\
981)\end{array}$ & $\begin{array}{c}18998(30 \\
371)\end{array}$ & $\begin{array}{c}-3625 \\
(-9915 \text { to } \\
2665)\end{array}$ & 0.448 \\
\hline $\begin{array}{l}\text { Plus parental } \\
\text { travel/ } \\
\text { productivity } \\
\text { losses }(n=132)\end{array}$ & $\begin{array}{c}15401(22 \\
908)\end{array}$ & $\begin{array}{c}18571(38 \\
215)\end{array}$ & $\begin{array}{c}-3170(-13 \\
852 \text { to } 7512)\end{array}$ & 0.341 \\
\hline $\begin{array}{l}\text { Multiple } \\
\text { imputation for } \\
\text { missing cases } \\
(n=366)\end{array}$ & $\begin{array}{c}17813(27 \\
690)\end{array}$ & $\begin{array}{c}23310(37 \\
826)\end{array}$ & $\begin{array}{l}-5497(-12 \\
312 \text { to } 1317)\end{array}$ & 0.184 \\
\hline
\end{tabular}

*Conversion rates at time of analysis: $£$ to $€, 1.4629$; $£$ to $\$, 1.8189$

(source: www.bankofengland.co.uk/statistics/index.htm).

†Adjusted for treatment centre, sex, baseline age, frequency and severity of self harm, stability of family situation, behavioural disorder,

depressive disorder, and baseline cost.

have deliberately poisoned themselves. I Am Acad Child Adolesc Psychiatry 1998;37:512-8.

16 Spirito A, Valeri S, Boergers J, Donaldson D. Predictors of continued suicidal behavior in adolescents following a suicide attempt. J Clin Child Adolesc Psychol 2003;32:284-9.

17 Pfeffer CR, Klerman GL, Hurt SW, Kakurma T, Peskin JR, Siefker CA. Suicidal children grow up: rates and psychological risk factors for attempts during follow-up. J Am Acad Child Adolesc Psychiatry 1993;32:106-13.

18 Beautrais AL. Risk factors for suicide and attempted suicide among young people. Aust N ZJ Psychiatry 2000;34:420-36.

19 Harrington R, Pickles A, Aglan A, Harrington V, Burroughs $\mathrm{H}$, Kerfoot $M$. Early adult outcomes of adolescents who deliberately poisoned themselves. J Am Acad Child Adolesc Psychiatry 2006;45:337-45.

20 Hawton K, Fagg J, Simkin S, Bale E, Bond A. Self-harm in adolescents in Oxford, 1985-1995. J Adolesc 2000;23:47-55.

21 Byford S, Barrett B, Harrington V, Aglan A, Burroughs H, Kerfoot M, et al. Lifetime and current costs of supporting young adults who deliberately poisoned themselves in childhood and adolescence. $)$ Mental Health 2009;18:297-306.

22 Romeo R, Knapp M, Scott S. Economic cost of severe antisocial behaviour in children and who pays it. Br J Psychiatry 2006;188:547-53. 
23 Byford S, Harrington R, Torgerson D, Kerfoot M, Dyer E, Harrington V, et al. Cost-effectiveness analysis of a home-based social work intervention for children and adolescents who have deliberately poisoned themselves. Results of a randomised controlled trial. $\mathrm{Br}$ J Psychiatry 1999;174:56-62.

24 Hawton KKE, Townsend E, Arensman E, Gunnell D, Hazell P, House A et al. Psychosocial and pharmacological treatments for deliberate self-harm Cochrane Database Syst Rev 1999;4:CD001764.

25 Wood A, Trainor G, Rothwell J, Moore A, Harrington RC. Randomized trial of group therapy for repeated deliberate self-harm in adolescents. J Am Acad Child Adolesc Psychiatry 2001;40:1246-53.

26 Hazell PL, Graham M, Mcgill K, Tracey K, Wood A, Trainor G, et al. Group therapy for repeated self-harm in adolescents: failure of replication of a randomized trial. J Am Acad Child Adolesc Psychiatry 2009;48:662-70.

27 Wood A, Harrington R, Moore A. Controlled trial of a brief cognitivebehavioural intervention in adolescent patients with depressive disorders. J Child Psychol Psychiatry 1996;37:737-46.

28 Linehan MM, Armstrong HE, Suarez A, Allmori D, Herad HL. Cognitive behavioural treatment of chronically parasuicidal borderline patients. Arch Gen Psychiatry 1991;48:1060-4.

29 Young JE, Beck AT. Cognitive therapy scale rating manual. [Unpublished manuscript.] University of Pennsylvania, 1980.

30 Angold A, Costello EJ, Messer SC, Pickles A. The development of a short questionnaire for use in epidemiological studies in depression in children and adolescents. Int J Meth Psychiatr Res 1995;5:237-49.

31 Daviss WB, Dirmahr B. Criterion validity of the mood and feelings questionnaire for depressive episodes in clinic and non-clinic subjects. J Child Adolesc Psychol Psychiatry 2006;47:927-34.

32 Reynolds WM. Suicidal ideation questionnaire: professional manual. Psychological Assessment Resources Inc, 1988.

33 Gowers SG, Harrington RC, Whitton A, Lelliott P, Beevor A, Wing J, et al. Brief scale for measuring the outcomes of emotional and behavioural disorders in children. Health of the Nation outcome scales for children and adolescents (HoNOSCA). Br J Psychiatry 1999;174:413-6.

34 Garralda ME, Yates P, Higginson I. Child and adolescent mental health service use. Br J Psychiatry 2000:177:52-8.

35 Barrett B, Byford S, Chitsabesan P, Kenning C. Mental health provision for young offenders: service use and cost. Br J Psychiatry 2006;188:541-6.

36 Byford S, Barrett B, Roberts C, Wilkinson P, Dubicka B, Kelvin RG, et al. Cost-effectiveness of selective serotonin reuptake inhibitors and routine specialist care with and without cognitive behavioural therapy in adolescents with major depression. Br J Psychiatry 2007;191:521-7.

37 Byford S, Barrett B, Roberts C, Clark A, Edwards V, Smethurst N et al. Economic evaluation of a randomised controlled trial for anorexia nervosa in adolescents. Br J Psychiatry 2007;191:436-40.

38 Curtis L, Netten A. Unit costs of health and social care. University of Kent at Canterbury, 2006.
39 Department of Health. NHS reference costs 2006. DH,2006.

40 National Audit Office. More than a roof: progress in tackling homelessness. NAO,2005.

41 British Medical Association \& Royal Pharmaceutical Society. British national formulary. BMA, 2006.

42 Metropolitan Police. MPS ready reckoner. Metropolitan Police Authority, 2000.

43 Harries R. The cost of criminal justice. Home Office Research Development and Statistics Directorate, 1999.

44 Finn W, Hyslop J, Truman C. Mental health, multiple needs and the police. Revolving Doors Agency, 2000.

45 Dubourg R, Hamed J. The economic and social costs of crime against individuals and households 2003/4. Home Office, 2005.

46 Independent Schools Council. ISC census 2007. ISC, 2007.

47 Legal Services Commission. General criminal contract. Legal Services Commission, 2003.

48 United Kingdom Parliament. Written answers, Hansard. DFES, 2007.

49 Automobile Association. Running costs for petrol cars. 2009. www. theaa.com/allaboutcars/advice/advice_rcosts_petrol_table.jsp.

50 Pritchard C, Sculpher M. Productivity costs: principles and practice in economic evaluation. OHE, 2002.

51 Elashoff JD. nQuery advisor. Version 3.0 user's guide. Statistical Solutions Ltd, 1999.

52 Kaufman J, Birmaher B, Brent D, Rao U, Flynn C, Moreci P. The schedule for affective disorders and schizophrenia for school aged children: present and lifetime version (K-SADS-PL). University of Pittsburgh, 1996.

53 Statacorp. Stata statistical software:rRelease 9. Stata Corp LP, 2006.

54 Efron B, Tibshirani RJ. An introduction to the bootstrap. Chapman \& Hall, 1993.

55 Thompson, Barber JA. How should cost data in pragmatic randomised trials be analysed? BMJ 2000;320:1197-200.

56 Byford S, Knapp M, Greenshields J, Ukoumunne OC, Jones V, Thompson S, et al, on behalf of the POPMACT Group. Costeffectiveness of brief cognitive behaviour therapy versus treatment as usual in recurrent deliberate self-harm: a rational decision making approach. Psychol Med 2003;33:977-86.

57 Fenwick E, Byford S. A guide to cost-effectiveness acceptability curves. Br J Psychiatry 2005;187:106-8.

58 Kessler RC, Borges G, Walters EE. The prevalence of and risk factors of lifetime suicide attempts in the National Comorbidity Survey. Arch Gen Psychiatry 1999;56:617-26.

59 Carter GL, Clover K, Whyte IM, Dawson AH, D'Este C. Postcards from the EDge project: randomised controlled trial of an intervention using postcards to reduce repetition of hospital treated deliberate self poisoning. BMJ 2005;331:805.

60 Kapur N, Cooper J, Bennewith O, Gunnell D, Hawton K. Postcards, greencards and telephone calls: therapeutic contact with individuals following self-harm. Br J Psychiatry 2010;197:5-7.

Accepted: 18 December 2010 